\title{
Monitoring and treatment for cardiovascular risk
}

\author{
Israel Rabinowitz, Ohad Hochman, Rachel Luzzati, Yelena Haifitz, Yuri Shclar, Natalia Kaykov, \\ Alexander Khemlin, Michael Kaffman and Ada Tamir
}

Department of Family Medicine, Clalit Health Services, Haifa and Western Galilee District, The Ruth \& Bruce Rappaport Faculty of Medicine, Technion-Israel Institute of Technology, Israel

\begin{abstract}
Background: In many countries there is a gap between the clinical evidence for cardiovascular disease (CVD) prevention and implementation in clinical practice. Inadequate control of cardiovascular risk factors and underutilization of aspirin, statins, angiotensin converting enzyme inhibitors and $\beta$-blockers are well-established examples. The optimal approach to implementation of CVD prevention in clinical practice is still under debate. The screening and monitoring (SaM) approach is based on cyclic monitoring and individual treatment of patients with cardiovascular risk factors in the primary care setting. After achieving improvements in risk factor levels and in the use of preventive medications in a pilot study, it was decided to test the efficacy of this approach in a larger population at risk. Methods: Five primary care clinics adopted the SaM approach. A total of 1622 patients with established CVD, diabetes mellitus or hypertension were assessed by their family physicians for cardiovascular risk factors and use of medications for cardiovascular risk reduction. Interventions were made according to accepted clinical guidelines. Cardiovascular risk factor levels and the use of medications for CVD prevention were retrospectively analyzed. Results: The results demonstrated significant reductions in blood pressure, hemoglobin $A_{1 c}$ and low-density lipoprotein-cholesterol levels, as well as significant increases in the use of medications for CVD prevention. Conclusion: A systematic approach to CVD reduction, with an emphasis on multiple risk factor assessment and use of preventive medications in patients at cardiovascular risk, yielded significant improvements in measures of the quality of preventive care.
\end{abstract}

Key words: cardiovascular diseases; primary health care; primary prevention; risk factors; secondary prevention

Received 31 March 2009; accepted 1 November 2009; first published online 10 December 2009

\section{Introduction}

Cardiovascular disease (CVD) is the leading cause of death in the developed world and is rapidly commanding the same position in developing countries (World Health Organization, 1997; Centers for Disease Control and Prevention, 2007a; 2007b). Risk factors for CVD have

Correspondence to: Israel Rabinowitz, Har Halutz, 20121 Israel. Email: Raly@netvision.net.il been defined and it is known that their modification considerably reduces cardiovascular morbidity and mortality. Powerful, evidence-based interventions for cardiovascular risk reduction have been available for some time. These include highly effective medications for dyslipidemia, hypertension, diabetes, patients with or at high-risk for CVD, patients after myocardial infarction and patients with congestive heart failure. However, despite their availability, use in practice is still far from satisfactory. Inadequate control of dyslipidemia, 
hypertension and diabetes, coupled with underutilization of aspirin, statins, angiotensin converting enzyme (ACE) inhibitors and $\beta$-blockers in groups of patients in which these are indicated, have been repeatedly reported. In patients with established coronary artery disease, in whom risk factor control is crucial, a survey of 1252 survivors of myocardial infarction in the US, demonstrated suboptimal management of hypertension with up to $50 \%$ of patients not reaching normal blood pressures $(\mathrm{BP}<140 / 90)$ and a low percentage of patients reaching their low-density lipoprotein (LDL)-cholesterol target levels (Qureshi et al., 2001). A similar survey of more than 24000 patients in Britain demonstrated unsatisfactory blood pressure control in patients with diabetes, suboptimal use of $\beta$-blockers in patients after myocardial infarction and of statins in patients with dyslipidemia (Brady et al., 2001).

This quality gap between evidence and practice has been targeted by cardiologists, epidemiologists, public health professionals and others who treat cardiovascular risk factors. However, solutions proposed by secondary or tertiary-care disciplines, unfamiliar with the dynamics and priorities of the family practice or primary care clinic may not lead to sustained improvements. It follows that primary care involvement is important in developing sustainable methods for CVD prevention. From a primary care perspective, we propose that this gap between evidence and practice arises mainly because of a suboptimal use of clinical information and a suboptimal approach to implementation.

\section{Suboptimal use of clinical information}

There is an abundance of information and guidelines. Entering the phrase 'cardiovascular disease prevention' in the search box of the National Guideline Clearinghouse website (www.guideline.gov), yields 471 guidelines, of which approximately 90 deal with one or more aspects of CVD prevention. Eighty-nine of these were published in the last five years. These guidelines are furnished by different disciplines, medical associations, public health organizations and expert consensus panels, on organizational, national and continental levels (Cabana et al., 1999; American College of Cardiology, 2002). It is clear that decisions have to be made as to how the clinician should manage this constantly swelling tide of information, particularly as high quality studies reviewing the effectiveness of guideline dissemination are lacking (Grimshaw et al., 2004).

Indeed, it has been shown that physicians' knowledge often lags some time after guidelines are updated, so years may elapse before new recommendations are assimilated into daily practice (Hyman and Pavlik, 2000). However, it does appear that, when clinicians adopt a specific set of guidelines, this facilitates the recognition of new recommendations when they are updated (Erhardt, 1999).

Some physicians appear to misunderstand the purpose of guidelines, perceiving them as a threat to professional autonomy and, in an era of managed care, as potentially biased by government policy or health insurance plans (Hayward et al., 1997). Ideally they would be free from commercial or political influence and seen as a scientific platform on which clinical judgment is based.

\section{Suboptimal approach to implementation}

This appears to result from shortcomings in the approach that many primary care physicians take to CVD prevention. Often there is an overreliance on case finding rather than screening. The majority of physician-patient encounters in primary care are problem-oriented and initiated by the patient (Binns et al., 2007). Screening for cardiovascular risk factors occurs therefore on a case-finding basis in a 10 min encounter in which the patient's focus is often on a different problem - the one that prompted the visit in the first place. This means that patients who do not visit the clinic do not receive CVD prevention and that, even for those who do attend, CVD prevention is discussed as a side issue during the clinical encounter.

Too often there is reliance on an intuitive rather than on a systematic approach to risk assessment. Cardiovascular prediction rules are available and recommended by guidelines to evaluate global cardiovascular risk. Indeed, a systematic review recently demonstrated that physicians' knowledge of global coronary heart disease risk scores may translate into reductions in CVD risk factors and increases in cardiovascular drug prescriptions (Sheridan and Crespo, 2008). However, in many countries, the use of prediction rules is relatively rare in primary care. 
In one study, conducted in Switzerland, approximately half the physicians questioned agreed with the statement: 'I do not use prediction rules as I know my patients well and can estimate their global risk correctly without a prediction rule'. A follow-up question revealed that approximately half the physicians made clinical decisions based on information about single risk factors (Eichler et al., 2007).

Focusing on single risk factors and diseases, instead of adopting a patient-centered approach that encompasses all the risks that are relevant to a particular individual underestimates their synergistic effects. It is important, therefore, without undermining the need for a thorough understanding of each particular risk factor, to start referring to 'the patient at cardiovascular risk'.

There is a dependency on a visit-to-visit regimen, rather than periodical follow-ups, which is a consequence of the patient-initiated nature of most clinical encounters in primary care. If CVD prevention is addressed in the encounter, the patient is usually instructed to return for a follow-up. At this point several scenarios are possible. The patient may indeed return for the follow-up and CVD prevention be addressed as the main issue of the encounter. The patient can return for a different problem and CVD prevention will again be addressed as a side issue. Also patients may not return in the recommended time interval if they misunderstand the physician's instructions, forget or opt not to if they feel well. Because failed patient appointments in ambulatory care are common, if the patient does not return for follow-up, (Weingarten et al., 1997), the chance that the primary care physician will notice this is slim.

\section{Development of an approach to cardiovascular risk reduction in primary care}

The screening and monitoring (SaM) approach was created by a family physician as a solution to the deficiencies noted in clinical information and implementation (Rabinowitz and Tamir, 2005). The approach was developed in the context of the Israeli primary health care system, in which public health services are provided by four health care operators that function under an obligatory national health law. A monthly progressive health tax is deducted from every citizen's income and no additional fees for primary physician services or laboratory tests are required. There is no limitation on the number of patient visits to primary care physicians and no pay-for performance program. While a full description of the SaM approach can be found at www.samapproach.com, a summary of its salient points is presented here.

\section{Clinical information}

For each major cardiovascular risk factor, one well established guideline (both in full-text and abbreviated form) is selected and adhered to over time. This is meant to facilitate familiarity, easy usage and quick orientation when a guideline is updated. Links to all guidelines and CVD risk calculators are incorporated into a single website (National Institute of Health, 1995; National Cholesterol Education Program, 2001; National Heart, Blood and Lung Institute-Joint National Committee, 2004; American Diabetes Association, 2008; US Public Health Service, 2008). Using consolidated guidelines for CVD prevention such as the European guidelines on cardiovascular disease prevention in clinical practice (www.guideline.gov) would be an alternative approach.

\section{Implementation}

The main feature of the SaM approach is the cyclic monitoring and individual treatment of patients at cardiovascular risk. The first step involves generation of a unified list of all patients in the clinic who have one or more major cardiovascular risk factors (Figure 1). This is done by a simple manipulation of the computerized medical record used in clinical practice (Rabinowitz and Tamir, 2005). The list is constructed according to the principle: high-risk patients first (Whiteley et al., 2005; Kerr et al., 2009). The second step involves monitoring the medical records of the patients on the list. Monitoring two medical records a day usually occupies no more than $10 \mathrm{~min}$ out of a $7-8 \mathrm{~h}$ workday, and can translate into a review of approximately 40 records a month. This means that in a busy urban clinic, similar to the ones described below, six to 12 months should suffice to monitor all patients on the list. This is appropriate, as six months is in the recommended follow-up interval for high risk

Primary Health Care Research \& Development 2010; 11: 29-40 


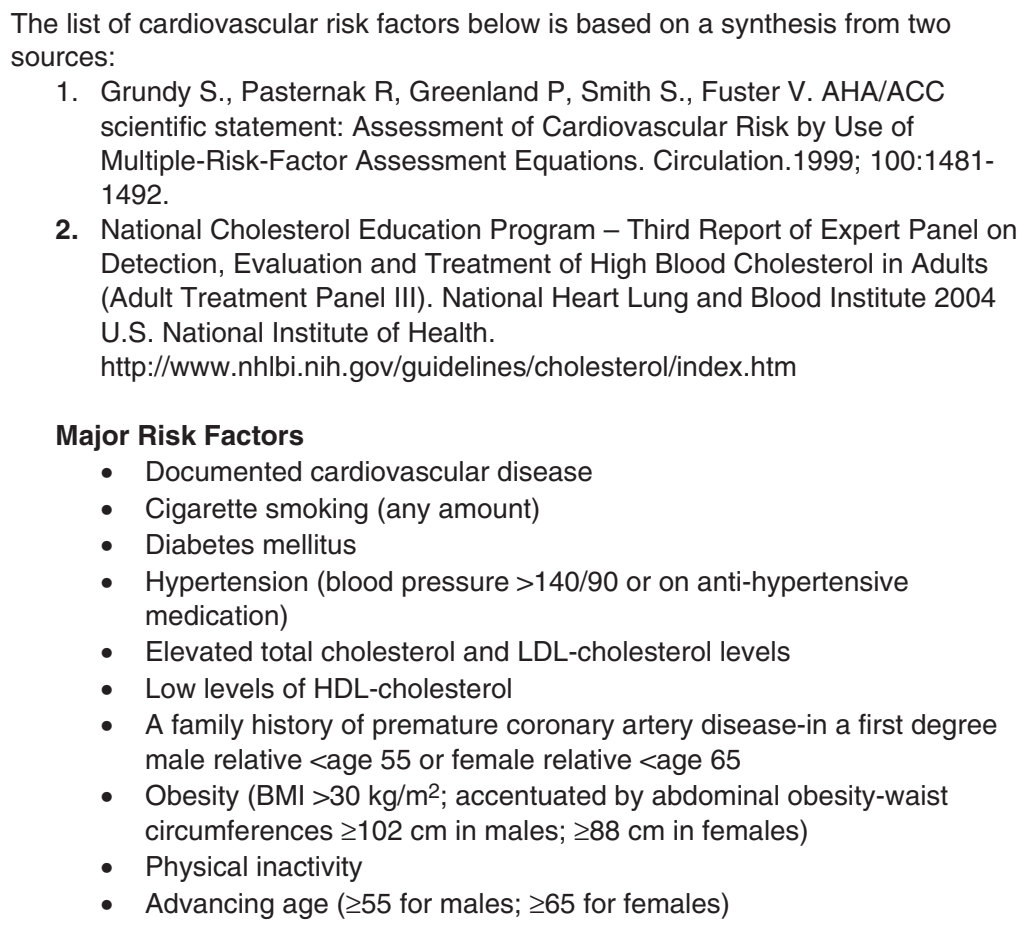

1. Grundy S., Pasternak R, Greenland P, Smith S., Fuster V. AHA/ACC scientific statement: Assessment of Cardiovascular Risk by Use of Multiple-Risk-Factor Assessment Equations. Circulation.1999; 100:14811492.

2. National Cholesterol Education Program - Third Report of Expert Panel on Detection, Evaluation and Treatment of High Blood Cholesterol in Adults (Adult Treatment Panel III). National Heart Lung and Blood Institute 2004 U.S. National Institute of Health. http://www.nhlbi.nih.gov/guidelines/cholesterol/index.htm

\section{Major Risk Factors}

- Documented cardiovascular disease

- Cigarette smoking (any amount)

- Diabetes mellitus

- Hypertension (blood pressure $>140 / 90$ or on anti-hypertensive medication)

- Elevated total cholesterol and LDL-cholesterol levels

- Low levels of HDL-cholesterol

- A family history of premature coronary artery disease-in a first degree male relative <age 55 or female relative <age 65

- Obesity (BMI >30 kg/m²; accentuated by abdominal obesity-waist circumferences $\geq 102 \mathrm{~cm}$ in males; $\geq 88 \mathrm{~cm}$ in females)

- Physical inactivity

- Advancing age ( $\geq 55$ for males; $\geq 65$ for females)

Figure 1 Cardiovascular risk factors - a list

patients with reasonably controlled risk factors (National Cholesterol Education Program, 2001; National Heart, Blood and Lung Institute-Joint National Committee, 2004; American Diabetes Association, 2008; US Public Health Service, 2008). Tighter follow-up is recommended for patients with significantly uncontrolled risk factors. Exceptions to treatment are made according to individual patient characteristics, such as adopting less demanding hemoglobin $\mathrm{A}_{1 \mathrm{c}}\left(\mathrm{HbA}_{1 \mathrm{c}}\right)$ target levels for frail elderly patients (American Diabetes Association, 2008).

The monitoring process focuses on the patient's current cardiovascular risk factors, on the degree of risk-modification achieved, on the appropriate use of medications in accordance with indications, with an emphasis on aspirin, statins, $\beta$-blockers and ACE inhibitors and culminates with operative conclusions. It is entered in the patient's medical record as a preventive visit and is thus available for review in the next monitoring cycle and also serves as documentation that CVD pre-

Primary Health Care Research \& Development 2010; 11: 29-40 vention was addressed in the recent past when the record is accessed in a routine visit. If indicated, patients are contacted to obtain information relevant to their assessment or the delivery of therapeutic interventions. This may be done by the physician or by a clinic nurse or administrator, according to local conditions. The monitoring protocol used was a paper template, also accessible at the website (Figure 2).

In this way the SaM approach ensures that a comprehensive cardiovascular risk assessment is performed periodically and independently of a patient's visits to the clinic. An additional advantage is that the number of reviews is reduced with a patient-focused (as opposed to a disease-focused approach), as illustrated in Figure 3.

\section{Method}

Following a lecture on the SaM approach at a continuing medical education session in Clalit 
(It's a good idea to print this page and have it in front of you when you actually begin working).

1. Does this patient have a Documented Cardiovascular Disease? $\mathrm{Y} / \mathrm{N}$.

If so, what is it and what are its manifestations?

2. What is this patients status regarding Life-Style Habits?

- Smoking of any amount

- Nutrition

- Physical activity- type and amount

3. In the past 6 months: have BMI, Blood Pressure, Serum Glucose (+HbA1C for Diabetics), Total Cholesterol, LDL-Cholesterol, HDL-Cholesterol and Triglyceride Levels Been Measured?

\begin{tabular}{|c|c|}
\hline Yes & No \\
\hline$\downarrow$ & $\begin{array}{c}\text { Request the above measurements and } \\
\text { laboratory tests }\end{array}$ \\
\hline \multicolumn{2}{|c|}{ After data is available - continue } \\
\hline
\end{tabular}

$\downarrow$

4. For each of the following risk factors fill in the relevant data:

\begin{tabular}{|c|c|c|c|c|c|c|}
\hline \multirow[t]{2}{*}{ Risk Factor } & \multirow[t]{2}{*}{ Present } & \multirow[t]{2}{*}{ Absent } & \multirow{2}{*}{$\begin{array}{l}\text { Target } \\
\text { value for } \\
\text { this patient }\end{array}$} & \multirow[t]{2}{*}{$\begin{array}{l}\text { Present } \\
\text { value }\end{array}$} & \multicolumn{2}{|c|}{$\begin{array}{l}\text { Satist. } \\
\text { control? }\end{array}$} \\
\hline & & & & & Yes & No \\
\hline Diabetes Mellitus & & & HBA1C & HBA1C $\%$ & & \\
\hline Hypertension & & & $\begin{array}{l}\text { Bloed } \\
\text { Pressure }\end{array}$ & $\begin{array}{l}\text { Bbod } \\
\text { Press. }\end{array}$ & & \\
\hline $\begin{array}{l}\text { Hypercholester. } \\
\text { (Elev. Total+LDL } \\
\text { Chol.) }\end{array}$ & & & LDL Chol. & LDL Chol. & & \\
\hline Low HDL Cholesterol & & & HDL Chol. & HDL Chol. & & \\
\hline Obesity & & & BMI & BMI: & & \\
\hline Abdominal Obesity & & & $\begin{array}{l}\text { Waist } \\
\text { Circumf. }\end{array}$ & Circ. & & \\
\hline
\end{tabular}

Figure 2 Monitoring protocol

Health Services' Department of Family Medicine in Haifa, five family physicians decided to implement the approach in their clinics. These were busy urban clinics serving a total of 7270 patients (ranging from 1074-1768 patients per clinic) and normally offered $10 \mathrm{~min}$ appointments for consultations. The implementation began in April 2005. Each physician received a list of patients who had one or more of the following diagnoses in their problem lists: established CVD (ischemic heart disease, cerebrovascular disease
5. Is there an indication for therapy with one of the following groups of medications?

\begin{tabular}{|l|l|l|l|l|l|}
\hline & Yes & No & \multicolumn{2}{|l|}{$\begin{array}{l}\text { Is t he patient taking } \\
\text { a medication from this } \\
\text { group }\end{array}$} & $\begin{array}{l}\text { If the answer is } \\
\text { no, is a } \\
\text { satisfactory } \\
\text { reason given ? }\end{array}$ \\
\hline & & Yes & No & \\
\hline Anti-Thrombotics & & & & & \\
\hline Beta-blockers & & & & & \\
\hline Statins & & & & & \\
\hline Ace-Inhibitor/ATR & & & & & \\
\hline antagonists & & & & \\
\hline
\end{tabular}

6. Summary of findings and operative conclusions:

- Begins with a short description of the cardiovascular disease/s and clinical manifestations if present.

- Continues and describes the patients cardiovascular risk factors, the interventions used for their modification and the degree of modification achieved.

- Reviews medications.

- Focuses on cardiovascular risk factors not yet satisfactorily modified.

- Concludes with on further steps to be taken. and peripheral artery disease) or type 2 diabetes or hypertension. The computerized medical record has been in use in the Clalit Health Service primary care system since 1997 and all clinical records were computerized. A review of a patient record took approximately $5 \mathrm{~min}$ and the process of reviewing the records occupied roughly one physician hour out of a full week's schedule for the duration of the study. The lengths of monitoring cycles varied according to the number of patients identified for each physician.

Primary Health Care Research \& Development 2010; 11: 29-40 
(a)

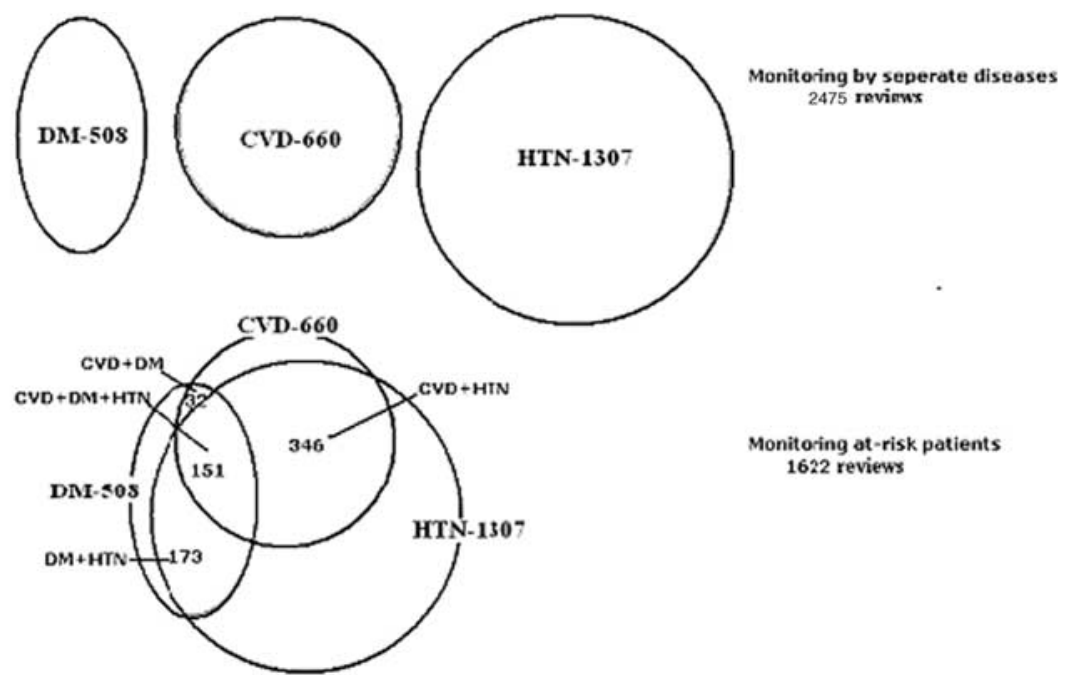

Figure 3 Disease overlap in the study population ad its effect on the number of reviews required to complete one monitoring cycle. Prevalence (a) and (b) of cardiovascular disease, diabetes mellitus and hypertension in the study population. Monitoring by seperate diseases would have required 2475 reviews. Monitoring at-risk patient required only 1622 reviews, due to disease overlap reducing the number of reviews by 823 (33\%). CVD-cardiovasular disease; DM-diabetes mellitus; HTN-hypertension. Number represent patients

In May 2008, patient files were analyzed for quality-of-care parameters relevant to cardiovascular risk reduction. Quality-of-care parameters were retrospectively recorded from two time points: the last parameter available before 30 March, 2005 (T0), and the last parameter available between 1 April, 2005 and 1 May, 2007 (T1).

These included: blood pressure levels for hypertensive patients and hypertensive patients with diabetes, $\mathrm{HbA}_{1 \mathrm{c}}$ for patients with diabetes, LDL-cholesterol levels, the use of antithrombotic medications, statins, $\beta$-blockers and ACE inhibitors or angiotensin receptor blockers (ARBs) when indicated. Data were analyzed using SPSS 14.0 software. The paired $t$-test was used to compare continuous variables and McNemar's test to compare dichotomous variables between two time points.

\section{Results}

\section{Patient population}

There were 1622 patients with established CVD or type 2 diabetes mellitus or essential hypertension (Table 1). The mean number identified at each clinic was 324 (range 567-141). An average

Primary Health Care Research \& Development 2010; 11: 29-40
Table 1 Patient characteristics

\begin{tabular}{lc}
\hline Baseline characteristics & Total number of patients 1622 \\
\hline Age & Mean-69.71; median-72; \\
& (SD-13.78) \\
Males/females $-n(\%)$ & $782(48.2 \%) / 840(51.8 \%)$ \\
Patients with CVD & $660(40.6)$ \\
Patients with diabetes & $508(31.3)$ \\
Patients with & $1307(80.5)$ \\
$\quad$ hypertension & \\
\hline
\end{tabular}

CVD $=$ cardiovascular disease

of 1.6 monitoring cycles was completed for the whole patient population. The degree of overlap of CVD, diabetes and hypertension in the patient population is shown in Figure 3.

\section{Change in risk factor levels}

The results for $\mathrm{T} 0$ and $\mathrm{T} 1$, along with the significance of change, are presented in Tables 2 and 3. Patient compliance was good for the different parameters measured: $84.8 \%$ for LDL-cholesterol measurements in patients with CVD, $87.5 \%$ for $\mathrm{HbA}_{1 \mathrm{c}}$ measurements in patients with diabetes mellitus and $81.3 \%$ for blood pressure measurements in patients with hypertension (Table 2). 
Table 2 Quality of care before (T0) and after (T1) implementation of screening and monitoring approach

\begin{tabular}{|c|c|c|c|c|}
\hline Quality of care parameter & Number & T0 & $\mathrm{T} 1$ & $\begin{array}{l}\text { Significance of } \\
\text { change T0-T1* }\end{array}$ \\
\hline Systolic BP in hypertensive patients ( $\mathrm{mmHg}$, mean and SD) & 1066 & 141.6 (SD19.8) & 136.1 (SD 18.5) & $P<0.0001$ \\
\hline Diastolic BP in hypertensive patients ( $\mathrm{mmHg}$, mean and SD) & 1063 & 79.8 (SD 9.9) & 76.7 (SD 10.8) & $P<0.0001$ \\
\hline $\begin{array}{l}\text { Systolic BP in hypertensive patients with diabetes }(\mathrm{mmHg} \text {, } \\
\text { mean and SD) }\end{array}$ & 277 & 145.0 (SD 21.8) & 137.2 (SD 20.8) & $P<0.0001$ \\
\hline $\begin{array}{l}\text { Diastolic BP in hypertensive patients with diabetes }(\mathrm{mmHg} \text {, } \\
\text { mean and SD) }\end{array}$ & 275 & 79.4 (SD 9.7) & 74.9 (SD 11.3) & $P<0.0001$ \\
\hline $\mathrm{HbA}_{1 \mathrm{c}}$ in patients with diabetes $(\%$, mean and SD) & 445 & 7.71 (SD 1.61) & 7.37 (SD 1.42) & $P<0.0001$ \\
\hline $\begin{array}{l}\text { LDL-cholesterol in patients with CVD (mg/dL (mmol/L), mean } \\
\text { and SD) }\end{array}$ & 560 & $107.6(5.97)(S D 31.0)$ & $97.3(5.40)(S D 31.1)$ & $P<0.0001$ \\
\hline $\begin{array}{l}\text { LDL-cholesterol in patients with diabetes }(\mathrm{mg} / \mathrm{dL}(\mathrm{mmol} / \mathrm{L}) \text {, } \\
\text { mean and SD) }\end{array}$ & 455 & $107.3(5.96)(S D 31.2)$ & $93.5(5.19)(S D 29.5)$ & $P<0.0001$ \\
\hline $\begin{array}{l}\text { LDL-cholesterol }(\mathrm{mg} / \mathrm{dL}(\mathrm{mmol} / \mathrm{L}), \text { mean) in CVD patients who } \\
\text { did not receive statins at T0 but did receive statins at T1 }\end{array}$ & 107 & $120.52(6.69)$ & $94.95(5.27)$ & $P<0.001$ \\
\hline $\begin{array}{l}\mathrm{LDL} \text {-cholesterol }(\mathrm{mg} / \mathrm{dL}(\mathrm{mmol} / \mathrm{L}), \text { mean) in diabetic patients } \\
\text { who did not receive statins at T0 but did receive statins at T1 }\end{array}$ & 128 & $116.58(6.47)$ & $94.25(5.23)$ & $P<0.001$ \\
\hline Use of aspirin in patients with CVD $(n) \%$ & 660 & (439) 66.5 & (467) 70.7 & $P<0.006$ \\
\hline$\beta$-Blockers in all patients $(n) \%$ & 1622 & (831) 51.3 & (896) 55.3 & $P<0.001$ \\
\hline ACE inhibitors or ARBs in patients with CVD or diabetes $(n) \%$ & 986 & (622) 63.0 & (668) 69.0 & $P<0.005$ \\
\hline ACE-inhibitors/ARBs in all patients $(n) \%$ & 1622 & (975) 60.1 & (1069) 65.9 & $P<0.001$ \\
\hline Statins in patients with CVD $(n) \%$ & 660 & (395) 59.8 & (492) 74.5 & $P<0.005$ \\
\hline Statins in patients with diabetes $(n) \%$ & 508 & (280) 55.0 & (401) 78.6 & $P<0.005$ \\
\hline
\end{tabular}

$\mathrm{BP}=$ blood pressure; $\mathrm{HbA}_{1 \mathrm{c}}=$ hemoglobin $\mathrm{A}_{1 c} . \mathrm{LDL}=$ low-density lipoprotein; $\mathrm{CVD}=$ cardiovascular disease; $\mathrm{ARBs}=$ angiotensin receptor

$\checkmark$ blockers; $A C E=$ angiotensin converting enzyme.

*For paired test on those with both measurements. 
Table 3 Percentage of patients with clearly elevated risk factor levels before (T0), and after (T1) implementation of the screening and monitoring approach

\begin{tabular}{lrrr}
\hline Quality of care parameter & T0 & T1 & $\begin{array}{r}\text { Significance of } \\
\text { change T0-T1* }\end{array}$ \\
\hline Hypertensive patients with systolic BP $>150 \mathrm{mmHg}(n) \%$ & $(404 / 1290) 31.3$ & $(267 / 1290) 20.6$ & $P<0.001$ \\
Hypertensive patients with diastolic BP $>90 \mathrm{mmHg}(n) \%$ & $(240 / 1287) 18.6$ & $(174 / 1287) 13.5$ & $P<0.001$ \\
Patients with LDL-cholesterol $>130 \mathrm{mg} / \mathrm{dL}(7.22 \mathrm{mmol} / \mathrm{L})(n) \%$ & $(386 / 1365) 28.2$ & $(263 / 1365) 19.2$ & $P<0.001$ \\
Patients with diabetes with $\mathrm{HbA}_{1 \mathrm{c}}>8 \%(n) \%$ & $(164 / 553) 29.6$ & $(132 / 553) 23.8$ & $P<0.001$ \\
\hline
\end{tabular}

$\mathrm{BP}=$ blood pressure; $\mathrm{LDL}=$ low-density lipoprotein; $\mathrm{HbA}_{1 \mathrm{c}}=$ hemoglobin $\mathrm{A}_{1 \mathrm{c}}$.

*For paired test on those with both measurements.

Average blood pressure decreased from 142/80 to $136 / 77 \mathrm{mmHg}$ in hypertensive patients and from $145 / 79$ to $137 / 74 \mathrm{mmHg}$ in hypertensive patients with diabetes. The number of patients with systolic blood pressure above $150 \mathrm{mmHg}$ decreased by $10.7 \%$. Mean $\mathrm{HbA}_{1 \mathrm{c}}$ in patients with diabetes decreased from $7.71 \%$ to $7.37 \%$ and the number of patients with $\mathrm{HbA}_{1 \mathrm{c}}$ above $8 \%$ also fell. LDL-cholesterol decreased from 107.6 $(5.97 \mathrm{mmol} / \mathrm{L})$ to $97.3 \mathrm{mg} / \mathrm{dL}(5.40 \mathrm{mmol} / \mathrm{L})$ in patients with CVD and from $107.3(5.96 \mathrm{mmol} / \mathrm{L})$ to $93.5 \mathrm{mg} / \mathrm{dL}(5.19 \mathrm{mmol} / \mathrm{L})$ in patients with diabetes. A $9 \%$ decrease in the number of patients with LDL cholesterol above $130 \mathrm{mg} / \mathrm{dL}$ (7.22 $\mathrm{mmol} / \mathrm{L})$ was demonstrated.

\section{Use of preventive medications}

The percentage of patients with CVD receiving aspirin increased by $4.2 \%$ (from $439 / 660$ to 467 / 660). The percentage of patients with CVD receiving a statin increased by $14.1 \%$ (from 395/ 660 to 496/660). The percentage of patients with diabetes receiving a statin increased by $23.6 \%$ (from 280/508 to 401/508), while the percentage of all patients at risk of CVD receiving ACEinhibitors/ARBs increased by $5.8 \%$ (from 975/ 1622-1069/1622). These increases were statistically significant.

\section{Discussion}

The ultimate goal of the SaM approach is the delivery of appropriate interventions to patients at cardiovascular risk, and the regulation of those interventions over time. A pilot study demonstrated that this goal is attainable with significant improvement in risk factor levels and use of indicated medications (Rabinowitz and Tamir,
2005). In this study, we demonstrated similar results in a busy family practice setting in a much larger high-risk population.

\section{Significance of results}

There are several points to be addressed under this heading. The first is the reduction in risk factor levels. The average reductions demonstrated were: $5.5 \mathrm{mmHg}$ in systolic blood pressure in hypertensive patients, $7.8 \mathrm{mmHg}$ in systolic blood pressure in hypertensive patients with diabetes, $0.34 \%$ percent in $\mathrm{HbA}_{1 \mathrm{c}}$ levels in patients with diabetes, $10.3 \mathrm{mg} /$ $\mathrm{dL}$ in LDL-cholesterol levels in patients with CVD and $13.8 \mathrm{mg} / \mathrm{dL}$ in LDL-cholesterol levels in patients with diabetes. The results were statistically significant and the recommended target levels were achieved in all groups, excluding the diabetic group, which nevertheless reached $0.37 \%$ from the $7.0 \%$ recommended target level.

Landmark trials such as the Systolic Hypertension in the Elderly Program (SHEP) study (SHEP Cooperative Research Group, 1991) and the Systolic Hypertension in Europe (Syst-Eur) Study (Staessen et al., 1997) have demonstrated significant reductions in stroke and coronary events (approximately 30\%), and heart failure (approximately $50 \%$ ) with reductions of $10-12 \mathrm{mmHg}$ in systolic blood pressure. The antihypertensive and lipidlowering treatment to prevent heart attack trial (ALLHAT Trial, 2002) with 42418 high-risk patients achieved similar results from a baseline blood pressure of $146 / 84 \mathrm{mmHg}$.

The reductions demonstrated in our study were somewhat lower $(5.5 \mathrm{mmHg}$ in systolic blood pressure in hypertensive patients, $7.8 \mathrm{mmHg}$ in systolic blood pressure in hypertensive patients with diabetes), but so were the baselines, with 
mean readings of $142.6 / 79.8 \mathrm{mmHg}$ and $145.0 /$ $79.4 \mathrm{mmHg}$, respectively. The greater reduction in blood pressure in the group of hypertensive patients with diabetes is especially important since tight blood pressure control in this group significantly reduces cardiovascular morbidity and mortality (UK Prospective Diabetes Study Group, 1998). Tighter glycemic control reduces risk for CVD. The United Kingdom Prospective Diabetes Study (UKPDS), found that with each $1 \%$ reduction in $\mathrm{HbA}_{1 \mathrm{c}}$ there was a $21 \%$ risk reduction for each end point related to diabetes (Stratton et al., 2000). The median $\mathrm{HbA}_{1 \mathrm{c}}$ levels achieved in the intensively treated group in the UKPDS was $7.0 \%$, but it is important to remember that patients in this study were enrolled at diagnosis, whereas the $\mathrm{HbA}_{1 \mathrm{c}}$ levels in our population reflect diabetes of various durations.

Lowering cholesterol reduces risk for CVD. LaRosa et al. (2005), in the discussion section of their study on intensive lipid lowering in patients with stable coronary artery disease, plot CVD event rates against LDL-cholesterol levels in major secondary prevention studies that used statins. It was clearly demonstrated that CVD events declined continuously as LDL levels dropped from $160 \mathrm{mg} /$ $\mathrm{dL}(8.88 \mathrm{mmol} / \mathrm{L})$ down to a level of $70 \mathrm{mg} / \mathrm{dL}$ (3.88 mmol/L) (LaRosa et al., 2005). The decline in LDL levels in our study fell along this continuum.

The second important finding is the increase in the use of medications for CVD prevention. Major trials have demonstrated the impact of aspirin, $\beta$-blockers, ACE inhibitors and statins on CVD morbidity and mortality. Aspirin reduced vascular mortality by $15 \%$ and CVD events by $30 \%$ in patients with CVD (Antiplatelet Trialists' Collaboration, 1994). An ACE inhibitor was shown to reduce CVD death, myocardial infarction or stroke by $22 \%$ in patients with CVD without left ventricular systolic dysfunction, or with diabetes and one additional risk factor (Yusuf et al., 2000). Statins reduced mortality in several well known large studies by more than $30 \%$ in patients with CVD (Scandinavian Simvastatin Survival Study (4S), 1994; Sacks et al., 1996; Long-Term Intervention with Pravastatin in Ischemic Disease Study Group, 1998) and in patients with CVD and/or diabetes (Heart Protection Study Collaborative Group, 2002). An overview of randomized trials from Journal of the American Medical Association (Hebert et al.,
1997) performed by Bandolier (Bandolier, 1998), found an number needed to treat (NNT) of 35 for primary prevention with statins to prevent stroke, myocardial infarction or death, and an NNT of 11 for secondary prevention.

Significant increases in the use of these specific classes of medications were achieved in our study population. It is noteworthy that 107 CVD patients and 128 patients with diabetes, who did not receive a statin at $\mathrm{T} 0$, received a statin at $\mathrm{T} 1$. In these groups, LDL-cholesterol levels were clearly above target and dropped by more than $20 \mathrm{mg} / \mathrm{dL}$ to target levels at T1 (Table 2). This is important in our view, because it indicates that the SaM approach, by ensuring that records are reviewed independently of the patient's visits to the clinic, identifies groups of untreated patients for whom treatment is clearly indicated.

Third, it is important to understand, that the effects of the above evidence-based interventions are synergistic. Combinations of statins, aspirin and $\beta$-blockers achieved an $83 \%$ reduction in allcause mortality in patients with ischemic heart disease in a large British Open Prospective Cohort Study (Hippisley-Cox and Coupland, $2005)$, and statins, $\beta$-blockers, aspirin, and ACE inhibitors were found to be associated with a reduction in long-term mortality in patients with peripheral vascular disease (Feringa et al., 2006).

A final point regarding the results is that in our study some of the parameters were not severely elevated when measured at baseline. The fact that significant improvement was still achieved in these parameters signifies that even greater improvements can be expected when applying the $\mathrm{SaM}$ approach to a population with poorer baseline parameters, as demonstrated in the subgroups of our study (Table 3).

\section{The SaM approach in context of previous multiple-intervention efforts}

The majority of CVD prevention trials have focused on single interventions (SHEP, 1991; ATC, 1994; 4S, 1994; Sacks et al., 1996; Staessen et al., 1997; UKPDS, 1998; LIPID, 1998; HPS, 2002), but as has been suggested, greater benefit my result from a coordinated approach. The United Kingdom National Health Service pay for performance program is an example of a nationalscale effort to increase performance against 146

Primary Health Care Research \& Development 2010; 11: 29-40 
clinical quality indicators, which include indicators relevant to CVD prevention. Approximately $80 \%$ of patients with hypertension and a similar percentage of patients with coronary artery disease were reported to have achieved target blood pressure levels (Doran et al., 2006). The evidence on the impact of the scheme is however mixed because a recent review found significant shortterm improvements in aspects of CVD that were linked to incentives, but a decline in aspects that were not. This suggests that efforts to reward preventive medicine need to be carefully targeted if they are not to have adverse effects on other aspects of care (Campbell et al., 2009).

A few trials have assessed the effect of multiple risk factor modification in subsets of patients. For example, a community-based multiple risk factor intervention on cardiovascular risk in black families with a history of premature coronary disease yielded decreases in blood pressure and LDL-cholesterol levels (Becker et al., 2005). An intensified multifactoral intervention - with tight glucose regulation and the use of renin-angiotensin system blockers, aspirin and lipid-lowering agents - reduced mortality from CVD among patients with type 2 diabetes mellitus and microalbuminuria (Gaede et al., 2008). Combination drug regimens have also been assessed in subsets of patients as described above (Hippisley-Cox and Coupland, 2005; Feringa et al., 2006). National and international surveys of risk factor management are periodically performed (EUROASPIRE II Study Group, 2001; Stafford and Radley, 2003). The significant results of these multiple intervention trials emphasize the need for a comprehensive approach to CVD prevention such as the one presented here.

\section{Limitations}

Limitations of both the approach developed and the study of its impact need to be addressed. A limitation of the SaM approach is that initial identification of at-risk patients is potentially limited by the accuracy of existing risk factor documentation, an inevitable situation brought about by the fact that one has to start from somewhere. However, it should be remembered that cardiovascular risk factors tend to aggregate in at-risk patients, and that the SaM approach includes a search for all major cardiovascular risk factors in each patient in each monitoring cycle.

Primary Health Care Research \& Development 2010; 11: 29-40
Thus identification of a patient by a single risk factor should lead to the unmasking of others in the same patient.

The limitations of the study are that it compares parameters before and after the intervention and lacks a control group. As such, some of the changes may have occurred anyway over time. An economic evaluation for possible increases in laboratory-associated costs was not performed. The significance of the improvements, however, and the achievement of target-level ranges are noteworthy, especially when compared to surveys from the USA, Britain and Europe (Querashi, et al., 2001; Brady et al., 2001; EUROASPIRE II Study Group, 2001; Stafford and Radley, 2003).

\section{Future directions and challenges}

It is our opinion that the main challenge for CVD prevention is the integration of methods such as the SaM approach into routine primary care. This means that the records of at-risk patients should be periodically reviewed, independently of patient visits to the clinic, for the presence of all major cardiovascular risk factors, the degree of risk factor control and the use of interventions for CVD prevention.

A wider implementation of such an approach depends on support at the educational, organizational and technological levels. At the educational level, especially in primary care, a comprehensive approach to CVD prevention should be emphasized. Recommended target levels and medications may change, but the necessity for a comprehensive approach will not. At the health system level, an incentive could include a reimbursed weekly hour for using an approach such as ours on an agreed number of patients. At the clinic level, one way of facilitating CVD prevention in primary care is through the use of non-physician personnel such as nurses or administrators with degrees of autonomy ranging from coordinating appointments for laboratory tests and physical measurements, to working as a case manager trained in comprehensive CVD prevention. At the technological level, computerized tools that are interfaced into the electronic medical record, are already in use and could be improved further (Sequist et al., 2005). By employing them methodically as part of an ongoing clinician-driven approach, their potential could be more fully realized. 


\section{Acknowledgments}

The authors thank Ms Tamar Rabinowitz for technical assisstance.

\section{Conflicts of interest}

None.

\section{References}

ALLHAT Trial. 2002: Major outcomes in high-risk hypertensive patients randomized to angiotensinconverting enzyme inhibitor or calcium channel blocker vs diuretic: the Antihypertensive and Lipid-Lowering Treatment to Prevent Heart Attack Trial. Journal of the American Medical Association 288, 2981-97.

American College of Cardiology. 2002: 33rd Bethseda Conference: preventive cardiology how can we do better? Journal of the American College of Cardiology 4, 579-651.

American Diabetes Association (ADA). 2008: Standards of medical care in diabetes. V. Diabetes care. Diabetes Care (Suppl 1), S16-24.

Antiplatelet Trialists' Collaboration. 1988: Secondary prevention of vascular disease by prolonged antiplatelet treatment. British Medical Journal 296, 320-31.

Antiplatelet Trialists' Collaboration. 1994: Collaborative overview of randomized trials of antiplatelet therapy - I. Prevention of death, myocardial infarction, and stroke by prolonged antiplatelet therapy in various categories of patients. British Medical Journal 308, 81-106.

Bandolier journal. 1998: Issue 47. Statins.

Becker, D.M., Yanek, L.R., Johnson, W.R. Jr. et al. 2005: Impact of a community-based multiple risk factor intervention on cardiovascular risk in black families with a history of premature coronary disease. Circulation 111, 1298-304.

Binns, J., Lanier, D., Pace, W.D. et al., for the Primary Care Network Survey. 2007: Describing Primary Care Encounters: the Primary Care Network Survey and the National Ambulatory Medical Care Survey. Annals of Family Medicine 5, 39-47.

Brady, A.J.B., Oliver, M.A. and Pittard, J.B. 2001: Secondary prevention in 24,431 patients with coronary heart disease: survey in primary care. British Medical Journal 322, 1463.

Cabana, M.D., Rand, C.S., Powe, N.R. et al. 1999: Why don't physicians follow clinical practice guidelines? A framework for improvement. Journal of the American Medical Association 282, 1458-65.

Campbell, M., Reeves, D., Kontopantelis, E., Sibbald, B. and Roland, M. 2009: Effect of Pay-for Performance on Quality of Primary Care in England. The New England Journal of Medicine 361, 368-78.

Centers for Disease Control and Prevention. 2007a: Heart Disease. National Vital Statistics Reports. 49. No. 8 - http:// www.cdc.gov/nchs/fastats/heart.htm
Centers for Disease Control and Prevention Stroke. 2007b: National Vital Statistics Reports. 49. No. 12 - http:// www.cdc.gov/nchs/fastats/stroke.htm

Doran, T., Fullwood, C., Gravelle, H., Reeves, D., Kontopantelis, E., Hiroeh, U. et al. 2006: Pay-for-performance programs in family practices in the United Kingdom. The New England Journal of Medicine 355, 375-84.

Eichler, K., Zoller, M., Tschudi, P. and Steurer, J. 2007: Barriers to apply cardiovascular prediction rules in primary care: a postal survey. BMC Family Practice 8, 1-7.

Erhardt, L.R. 1999: The essence of effective treatment and compliance is simplicity. American Journal of Hypertension $12,105 \mathrm{~s}-10 \mathrm{~s}$.

EUROASPIRE II Study Group. 2001: Lifestyle and risk factor management and use of drug therapy in coronary patients from 15 countries; principle results from the EUROASPIRE II Euro Heart Survey Program. European Heart Journal 22, 554-72.

Feringa, H.H., van Wanin, V.H., Bax, J.J. et al. 2006: Cardioprotective medication is associated with improved survival in patients with peripheral arterial disease. Journal of the American College of Cardiology 47, 1182-87.

Gaede, P., Lund-Andersen, H., Parving, H.H. and Pedersen, O. 2008: Effect of a multifactorial intervention on mortaliy in type 2 diabetes. The New England Journal of Medicine 358, 580-91.

Grimshaw, J.M., Thomas, R.E. and Maclennan, G. 2004: Effectiveness and efficiency of guideline dissemination and implementation strategies. Health Technology Assessment Journal 8, 1-72.

Hayward, R.S., Guyatt, G.H., Moore, K.A., McKibbon, K.A. and Carter, A.O. 1997: Canadian physicians' attitudes about and preferences regarding clinical practice guidelines. Canadian Medical Association Journal 156, 1715-23.

Heart Protection Study Collaborative Group. 2002: MRC/ BHF Heart Protection Study of cholesterol lowering with simvastatin in 20,536 high-risk individuals: a randomized placebo-controlled trial. Lancet 360, 7-22.

Hebert, P.R., Gaziano, J.M., Chan, K.S. and Hennekens, C.H. 1997: Cholesterol lowering with statin drugs, risk of stroke, and total mortality. Journal of the American Medical Association 278, 313-21.

Hippisley-Cox, J. and Coupland, C. 2005: Effect of combinations of drugs on all cause mortality: nested casecontrol analysis in patients with ischemic heart disease. British Medical Journal 330, 1059-63.

Hyman, D.J. and Pavlik, V.N. 2000: Self reported hypertension treatment practices among primary care physicians: blood pressure thresholds, drug choices and the role of guidelines and evidence-based medicine. Archives of Internal Medicine 160, 2281-86.

Kerr, A.J., Broad, J., Wells, S., Riddell, T. and Jackson, R.T. 2009: Should the first priority in cardiovascular risk management be those with prior cardiovascular disease? Heart 95, 125-29.

Primary Health Care Research \& Development 2010; 11: 29-40 
LaRosa, J.C., Grundy, S.M., Waters, D.D. et al. 2005: Intensive lipid lowering with Atorvastatin in patients with stable coronary disease. The New England Journal of Medicine $352,1425-35$.

Long-Term Intervention with Pravastatin in Ischemic Disease (LIPID) Study Group. 1998: Prevention of cardiovascular events and death with pravastatin in patients with coronary heart disease and a broad range of initial cholesterol levels. The New England Journal of Medicine 339, 1349-57.

National Institute of Health Consensus Statement Online. 1995. Physical Activity and Cardiovascular Health. December 18; 13(3): 1-33. http://consensus.nih.gov/1995/ 1995ActivityCardivascularHealth101html.htm

National Cholesterol Education Program. Third Report of the Expert Panel on Detection, Evaluation and Treatment of High Blood Cholesterol in Adults. (Adult Treatment Panel III) 2001. U.S. National Institute of Health.

National Heart, Blood and Lung Institute. 2003: The seventh report of the Joint National Committee on prevention, detection, evaluation, and treatment of high blood pressure (JNC 7) 2003. US Department of Health and Human Services.

Qureshi, A.I., Suri, M.F., Guterman, L.R. and Hopkins, L.N. 2001: Ineffective secondary prevention in survivors of cardiovascular events in the US population: report from the Third National Health and Nutrition Examination Survey. Archives of Internal Medicine 103, 38-44.

Rabinowitz, I. and Tamir, A. 2005: The SaM (Screening and Monitoring) approach to cardiovascular risk-reduction in primary care - cyclic monitoring and individual treatment of patients at cardiovascular risk using the electronic medical record. European Journal of Cardiovascular Prevention and Rehabilitation 1, 56-62.

The SaM approach to cardiovascular risk-reduction in primary care. Rabinowitz, I. 2003. http://www.samapproach.com

Sacks, F.M., Pfeffer, M.A., Moye, L.A. et al. 1996: The effect of pravastatin on coronary events after myocardial infarction in patients with average cholesterol levels. Cholesterol and Recurrent Events Trial investigators. The New England Journal of Medicine 335, 1001-09.

Scandinavian Simvastatin Survival Study (4S). 1994: Randomized trial of cholesterol lowering in 4444 patients with coronary heart disease. Lancet 344, 1383-89.

Sequist, T.D., Gandhi, T.K., Karson, A.S. et al. 2005: A randomized trial of electronic clinical reminders to improve quality of care for diabetes and coronary artery disease. Journal of the American Medical Informatics Association 12, 431-37.
SHEP Cooperative Research Group. 1991: Prevention of stroke by antihypertensive drug treatment in older persons with isolated systolic hypertension: final results of the Systolic Hypertension in the Elderly Program (SHEP). Journal of the American Medical Association 265, 3255-64.

Sheridan, S.L. and Crespo, E. 2008: Does the routine use of global coronary heart disease risk scores translate into clinical benefits or harm? A systematic review of the literature. BMC Health Services Research 8, 60-73.

Staessen, J.A., Fagard, R., Thijs, L. et al., for the Systolic Hypertension in Europe Trial Investigators. 1997: Randomized double-blind comparison of placebo and active treatment for older patients with isolated systolic hypertension. Lancet 350, 757-64.

Stafford, R.S. and Radley, D.C. 2003: The underutilization of cardiac medications of proven benefit - 1990 to 2002. Journal of the American College of Cardiology 41, 56-61.

Stratton, I.M., Adler, A.I., Neil, H.A. et al. 2000: Association of glycemia with macrovascular and microvascular complications of type 2 diabetes (UKPDS 35): prospective observational study. British Medical Journal 321, 405-12.

UK Prospective Diabetes Study Group. 1998: Tight blood pressure control and risk of macrovascular and microvascular complications in type 2 diabetes: UKPDS 38. British Medical Journal 317, 703-13.

US Public Health Service. 2008: Treating Tobacco use and dependence - a quick reference guide for clinicians. update. http://www.guideline.gov/summary/summary.aspx? doc $\_i d=12520 \& n b r=6444 \& s s=6 \& x l=999$

Weingarten, N., Meyer, D.L. and Schneid, J.A. 1997: Failed appointments in residency practices: who misses them and what providers are most affected? Journal of the American Board of Family Practice 10, 407-11.

Whiteley, L., Padmanabhan, S., Hole, D. and Isles, C. 2005: Should diabetes be considered a coronary heart disease risk equivalent? Results from 25 years of follow-up in the Renfrew and Paisley survey. Diabetes Care 28, 1588-93.

World Health Organization. 1997: World health report executive summary. http://www.who.int/whr/1997/exsum97e.htm

Yusuf, S., Sleight, P., Pogue, J., Bosch, J., Davies, R. and Dagenais, G. 2000: Effects of an angiotensin-convertingenzyme inhibitor, ramipril, on cardiovascular events in high-risk patients. The Heart Outcomes Prevention Evaluation Study Investigators. The New England Journal of Medicine 342, 145-53. 